\title{
Integrating True Short Stories into English Classes: The Case of Foundation Students in Oman
}

\author{
Munira Said Al Siyabi ${ }^{1}$ \\ ${ }^{1}$ English Language and Literature Department, Rustaq College of Applied Sciences, Rustaq, Sultanate of Oman \\ Correspondence: Munira Said Al Siyabi, English Language and Literature Department, Rustaq College of \\ Applied Sciences, Rustaq, Sultanate of Oman. E-mail: munirasaid2011@hotmail.com
}

Received: January 1, 2017 Accepted: February 18, 2017 Online Published: February 20, 2017

doi: 10.5539/elt.v10n3p164 URL: http://doi.org/10.5539/elt.v10n3p164

\begin{abstract}
Searching for practical ways to improve students' English language skills is a real concern for all English teachers. There is a consensus among ELT practitioners regarding the significance of reading for learning new languages, since reading gives depth to language learning (Stern, 2001). Thus, teachers are obligated to provide their students with interesting and suitable texts to read. Real stories are by far more interesting and involving than scientific and historical texts. The present study aimed to investigate students' perceptions of reading true short stories and its benefits. The study data were collected through a survey and participant observation of 19 level D students in Oman. The study findings indicated that using stories during English class was an interesting experience and had good potential as a tool to improve English language skills. The meaningful context created by the true short stories made it much easier for the teacher to conduct and run the class.
\end{abstract}

Keywords: linguistic skills, potential, students' perceptions, true short stories

\section{Introduction}

Reading has been linked to academic performance, as students who tend to read regularly perform much better than those who do not read regularly (Guthrie, 2008, as cited in Al-Mahrooqi \& Denman, 2016). Reading is therefore an essential skill that should be adequately addressed. Being a competent reader will make it easier for the student to obtain the needed exposure to the target language, which in turn will facilitate the development of the other skills needed to be a language user. Living in a foreign language context minimizes the chances of listening to meaningful input. Thus, reading is the best way to sustain the development of students' language competency. However, Cobb (1999, as cited in Al-Mahrooqi, 2012) found that reading is the weakest skill among Omani college freshmen. Therefore, Omani teachers should seek interesting texts to ensure students' involvement; a suitable literary text could be sufficient for this purpose.

Butler (2002) used the phrase "language through literature" (p. 38) to describe the use of literature or literary texts as a medium for teaching the English language. The use of literature in language classes was rare and not very desired, as many teachers were more interested in empowering students with linguistic knowledge, which some believes has no relation to literature. Topping (1968) was one of the scholars against the inclusion of literature; he argued that "literature has no legitimate place in a second language programme" (p. 95). Although the integration of short stories into language classes has been criticized, many studies have proven that using authentic materials in general and short stories in particular, specifically in English language classes, has a positive impact on students' performance (Butler, 2002; Goldberg, 2006; Waters, 2009). An awareness of these benefits can motivate researchers and teachers to seek the best ways to integrate literature into the English language classroom. Students' awareness of these benefits can also make the practice more successful. This study attempts to explore level D students' perceptions of integrating literature into the English language classroom.

\section{Review of Related Literature}

\subsection{True Stories as Teaching Materials}

True stories are good teaching materials because they provide students with "rich exposure to English literature" (Tomlinson, 1985, as cited in Butler, 2002, p. 37). Wong, Kwok, and Choi (1995) mentioned that the "genuineness of time, location and people" distinguishes authentic materials from contrived ones; these elements 
are represented in literature. True stories are authentic materials, since they represent real events and pass on the true beliefs of the targeted cultures or contexts. Thus, literature is full of authentic input (Ghosn, 1998). This input might be more meaningful to students than the input from other kinds of texts. Students' interaction with real events and characters will motivate them to continue reading and create a meaningful context for new learning.

\subsection{True Short Stories and Authenticity}

According to Roberts and Cooke (2009, p. 621), "The debate over authenticity in teaching materials is a longstanding and sometimes contradictory one in English language teaching." In 1970, a new approach emerged in the language learning and teaching field: the communicative language teaching approach. Since then, a significant debate has persisted regarding whether to expose learners not only to "artificially constructed texts" in classrooms (Waters, 2009, p. 138) but also to authentic texts. Authenticity in relation to materials, or what Johnson (1998) and Badger and Macdonald (2010) called product authenticity, has been defined as "a stretch of real language, produced by a real speaker or writer for a real audience and designed to convey a real message of some sort" (Gilmore, 2007, p. 98).

However, Waters (2009) stated that it is not easy to find authentic text that includes enough examples of the focus language and is simultaneously interesting and suitable to the learners' level. In response to this, Widdowson (1978, as cited in Guariento \& Morley, 2001, p. 349) declared that these materials can be simplified without losing their authenticity. Such simplification will enable students to enjoy the content without struggling with the language, whose complexity might hinder students' progress and continuity in tackling the text.

\subsection{Potential Benefits of Integrating True Short Stories into English Classes}

Advocates of literature inclusion in language classes have identified various advantages of such inclusion or incorporation. Brumfit and Carter (1986, as cited in Pathan, 2012) argued that integrating short stories into language classes may improve students' language skills more efficiently. Studies have also proven that reading has a positive influence on students' academic performance because reading "nurture[s] all the other language skills" (Alderson, 1984, as cited in Al-Mahrooqi, 2012, p. 25). Among the various benefits found, five are discussed in this paper: increasing motivation, developing reading comprehension, vocabulary acquisition, enhancing writing skill, and encouraging meaningful talk.

First, using true short stories in class increases students' motivation because such stories are "intrinsically more interesting" (Peacock, 1997, p. 144). Good true short stories attract students' attention, which ensures that they remain on task. True short stories provide students with insight into the target culture (Goldberg, 2006). They also pass on beliefs and values of other cultures, which encourages students to continue reading to satisfy their curiosity. Fawkes (2001, p. 2) argued that authentic materials, including short stories, "highlight similarities and differences in everyday customs and life"; thus, students gain a real knowledge of the world by exploring authentic materials.

Second, the positive impact of using short stories in developing reading comprehension has long been acknowledged in the ELT field (Pathan, 2012). Using true short stories in English classes will encourage students to read more even outside class. Stories are generally very good for extensive reading, and such a practice gives students the chance to guess meaning in reading (Khatib, Rezaei, \& Derakhshan, 2011). Encouraging such exposure will ensure the improvement of their reading skills and strategies. Generally, short stories follow a simple structure, and the sequence of events makes it even easier to understand the presented texts.

Third, authentic materials enable students to see how words are used in real contexts, which allows learners "to gain an understanding of how lexis functions in real-world environments" (Willis, 1993, as cited in Friedman, 2011, p. 126). Thus, learners gain a valuable opportunity to see the new words used in a real context and to revisit the words they already know. Siahaan $(2012$, p. 210) also argued that the story context, including the events of the story and the actions of the involved characters, "invite[s] active meaning making." This helps students learn new words without direct instruction from their teachers. Elley (1989, as cited in Siahaan, 2012) also mentioned that students' knowledge of words increases after reading a story thrice without teacher involvement. Chan (1999, as cited in Rashid, Vethamani, \& Abdul Rahman, 2010, p. 89) claimed that literature is illustrative of various "patterning of words and sounds." Thus, reading stories familiarizes learners with the collocation of the targeted words and their spelling. Overall, stories offer a sufficient opportunity for learning and recycling the meaning and form of the encountered words.

Fourth, reading literature exposes students to "the formation and function of sentences, the diversity of possible structures and the different ways of linking ideas" (Collie \& Slater, 1987, as cited in Rashid et al., 2010, p. 89). 
Due to frequent exposure to literature, various structures will be unconsciously embedded in students' writings, which will enrich their writing styles. Stories also represent the smooth transition and connectivity of ideas, which is always needed in a good piece of writing. Butler (2002) indicated that literature includes authentic models that help students see how different structures and words are normally used. These models will assist students in making natural use of various words and structures to reach a sufficient level in the targeted language. A good writer is always a good reader, and a literary text is a good model of a sufficient piece of writing.

Fifth, students' interaction with the literary text provides good opportunities to enhance their communication skills (Tomlinson, 1995, as cited in Butler, 2002). Stories may set an issue to be discussed or traditions to be compared, which encourages students to talk and express their opinions. These discussions take place in a stress-free environment because they are open to subjectivity. Stories also contain authentic dialogues, exposing students to everyday English, which the students eventually apply in their daily lives (Pathan, 2012). Since stories are easy to memorize or remember, different chunks of these stories are easily stored in students' minds and can be recalled in later conversations.

\section{Statement of the Problem}

The English language is gaining increasing importance in the Sultanate of Oman. Almost all universities and colleges in Oman use English-based instruction, which expands students' chances of being exposed to the English language. Students are also required to have an excellent command of English to perform well in their specializations. These English programs must find sufficient methods to increase their students' willingness to explore the English language. Many programs focus on reading because it provides foreign-language learners with the needed exposure to the target language. However, encouraging students to read during their spare time might not work with low-motivated students. Thus, teachers should incorporate reading time into their classes. True short stories are useful materials for such classes because they are short and manageable; their genuineness might also encourage students to be attentive and on task. The goals of this study are to find out students' perceptions of using true short stories in English classes and to examine the benefits gained from frequent exposure to English true short stories.

\subsection{Research Questions}

The research questions are as follows:

1) What are students' perceptions of using true short stories in their English classes?

2) What benefits do students gain from reading true short stories in their English classes?

\subsection{Study Context}

Oman is a Gulf country that is highly concerned about education and enhancing its citizens' English proficiency. The Ministry of Higher Education was established in 1994 to prepare well-educated youth to meet the needs of the local market. After earning their general diploma, Omani students are enrolled in different colleges, including the Colleges of Applied Sciences (CAS). Students accepted in CAS are first enrolled in a foundation program, where they are divided into four levels: A, B, C, and D. They take a placement test and are assigned to different levels based on their score in English. Students who receive very low marks (below 18 out of 70) are assigned to level D; these students usually have poor English skills and low motivation. After completing the foundation program, these students join one of the programs in their colleges.

The study was conducted on a level D group in one of these colleges. Level D students know little English and are usually trouble makers. Teachers feel hesitant to teach this level because it is tough to keep the students on task. The students are taught the English language 20 hours a week for 14 teaching weeks. Ten of these hours are for general English, where teachers depend on the New Headway Plus (beginner) books, while the other 10 hours are used to focus on reading, writing, and grammar. The teachers rely on the book Keep Writing (level 1) to teach writing skill; they decide on the needed materials for the other skills. Hence, selecting the materials for reading skill is up to the teacher. In this study, the teacher decided to use the book More True Stories for a High-Beginning Reader. This book includes various interesting true short stories. Students were exposed to one story for two hours per week. The teacher hoped that bringing something real to the class would involve students more and increase their concentration span.

The teacher started each short-story class by discussing the theme of the story; this set an appropriate context for the new story. Next, the students were asked to read the new story silently and then read it aloud. After reading the story aloud, the students were encouraged to summarize the story orally. They then answered some comprehension questions. As homework, the students were required to prepare a written summary of the studied story. Along with the summary, they were asked to write short sentences using the new words they learned from 
the stories.

\section{Methodology}

\subsection{Participants}

The nature of this research is exploratory, as it explores students' perceptions of using short stories in English classes and its potential benefits. Since this is a classroom action research study, the participants are all the students in a level D English class in a college in Oman, more specifically 18 male students. All the students are 18-19-year-old Omanis whose mother tongue is Arabic. The students' English level is very basic due to their low exposure to the English language in primary and secondary schooling.

\subsection{Instruments}

The study used a mixed methodology or triangulation, which was defined by Denzin (1978, as cited in Jick, 1979, p. 602) as "the combination of methodologies in the study of the same phenomenon." Jick (1979) stated that quantitative and qualitative methods complement each other, which may increase the reliability of the study. The qualitative method can also provide a sequential explanation of the quantitative findings.

The main source of data was a survey questionnaire composed of 10 closed-ended items and two open-ended questions. The questions were categorized into two main themes: students' perceptions of the short-story classes and the linguistic benefits gained from reading short stories. The questionnaire was in English, and the teacher was present if the students needed any clarifications. The qualitative method used in this study was participant observation; the researcher observed the students during the story classes and analyzed their summaries of the studied stories to follow their progress.

\section{Results and Discussion}

\subsection{Students' Perceptions of Using True Short Stories in English Classes}

Gambrell (1996) argued that the teacher has a major role in assessing students' development as readers. In this study, the class teacher devoted one class a week to reading a true short story, which was supposed to foster the students' love of reading. Figure 1 shows the students' perceptions of these classes.

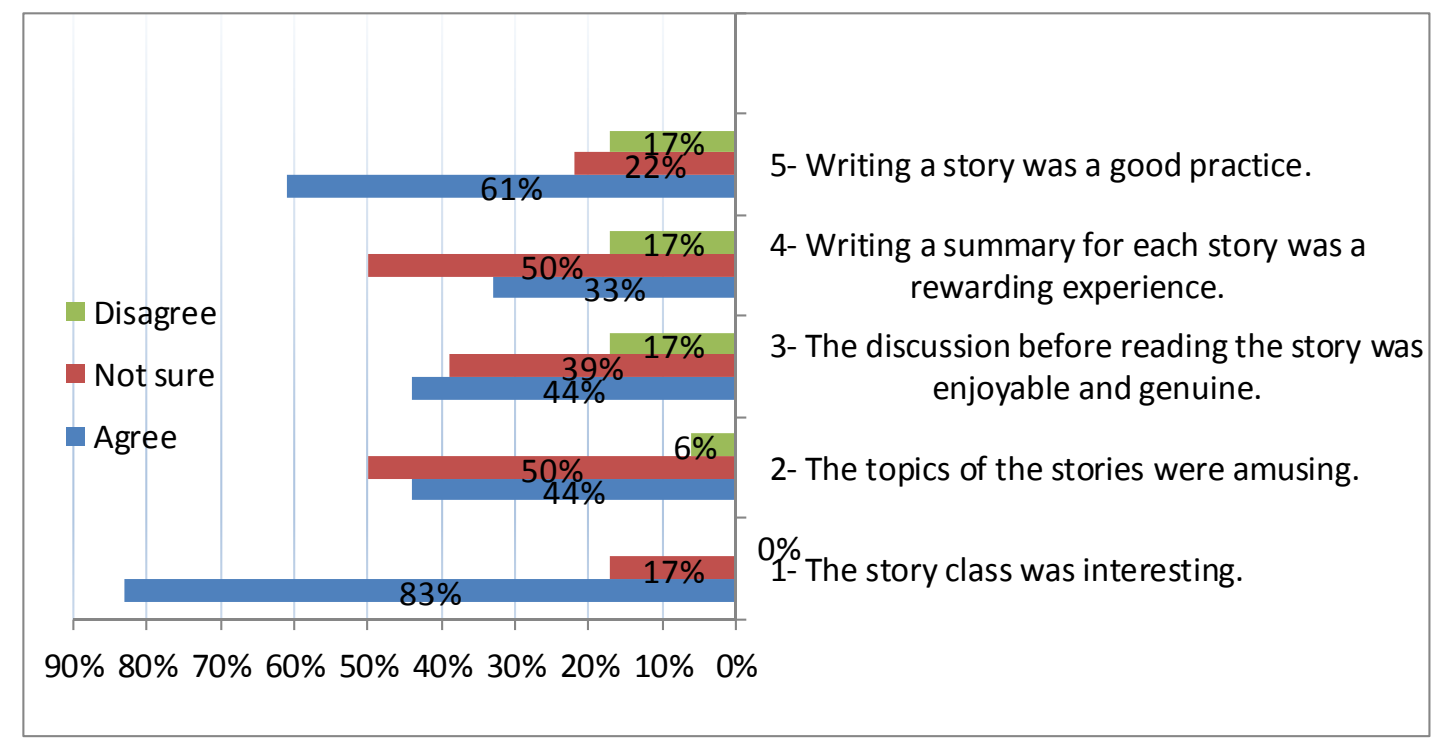

Figure 1. Students' perceptions of the short-story classes

Figure 1 presents the results for five items on students' perceptions of the short-story classes. The results indicate that the students enjoyed the story classes. The majority $(83 \%)$ agreed that the story class was interesting. A considerable proportion (44\%) agreed that the topics of the short stories were amusing, $50 \%$ were not sure, and only $6 \%$ disagreed. Teachers can do a quick interest survey at the beginning of the course to find out how to raise students' interest in the class. When asked about the warm-up discussion to activate their background knowledge about the theme of the story, $44 \%$ of the students said they enjoyed the discussion and sharing their ideas, $39 \%$ were not sure how they felt about it, and $17 \%$ disagreed that the discussion was enjoyable. As for the practice of writing a summary of each studied story, only a third $(33 \%)$ of the students agreed that writing a summary of 
each studied story was a rewarding experience. This may be because the students did not understand the benefits of writing a summary. Finally, most (61\%) of the students perceived writing their own stories as a good practice, $17 \%$ disagreed that it was a good practice, and $22 \%$ were not sure of its effectiveness. Overall, the students reacted positively to these classes and were relaxed and involved.

\subsection{Benefits of Reading True Short Stories in English Classes}

Wright (2008) stated that reading stories develops language awareness, as students are introduced to various vocabularies and language structures that they might not yet be producing at that stage.

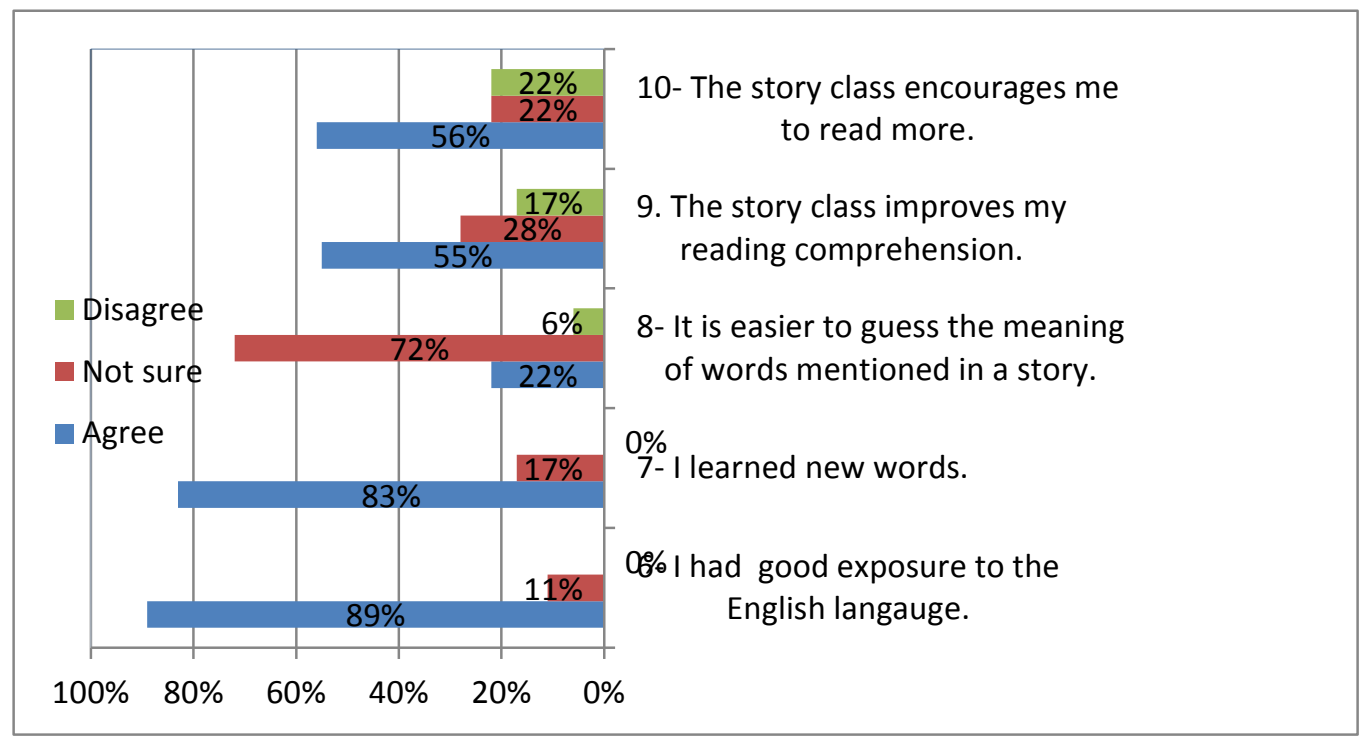

Figure 2. Linguistic benefits of reading short stories

Figure 2 shows that the students were aware of the linguistic benefits they gained from reading stories. Almost all the students (89\%) agreed that they had good exposure to the English language, while 11\% were not sure if they did. Generally, reading exposes students to various vocabularies and structures; reading short stories is no exception. This was illustrated by the fact that $83 \%$ of the students agreed that they had expanded their vocabulary; only $17 \%$ were not sure whether they had expanded their vocabulary, possibly because, as Wright (2008) said, they were not yet in the production stage. This result was expected because students were frequently using some of the learned vocabulary during class. For instance, two of the students used the words "survive and ran out of," which they came across in the last story discussed in class. This impressed their assessor during the speaking exam. Many of the learned vocabulary words were useful because they were used in a real context that was similar to what the students experienced every day. However, only $22 \%$ agreed that it was easier to guess the meaning of a word within the story context; the majority $(77 \%)$ were not sure and only $6 \%$ disagreed. Level D students were provided with dictionaries and encouraged to use them in all classes, which limited their chances of guessing the meaning of unknown words. Slightly over half (55\%) agreed that story classes improved their reading comprehension abilities, $28 \%$ were not sure, and $17 \%$ disagreed. Finally, $56 \%$ of the students agreed that these classes enhanced their reading habit, while $22 \%$ were not sure and $22 \%$ disagreed.

\subsection{Potential of True Short Stories for EFL Learners}

When asked about the other benefits gained from reading true short stories in English classes, some students mentioned an improvement in their oral communication as a result of the new learned vocabulary and being involved in discussing the themes of the stories. Wright (2008, p. 5) stated that one reason for using stories is their "stimulus for speaking and writing." The studied stories laid a good foundation for discussing different topics, which positively affected students' performance on the oral tasks and speaking exam. The discussion took place in a stress-free environment, where students were asked to express their opinions and share their experiences in relation to the discussed topic.

The students were involved in many tasks to ensure that they reached the mastery level of comprehension. All the students were asked to write a summary after each studied story. The students were highly committed to submitting the summary of each story on time. Although students at this level are expected to struggle to produce 
comprehensive summaries, the students' summaries were impressive. The students were able to locate the main events in the given stories. They were also required to write new endings for some stories and to create plays out of the other stories. While all the students did well in writing summaries, some also managed to write interesting new endings. Writing a new ending is not an easy task because students need to understand the previous events to create an appropriate ending. However, the students found it truly interesting to create different endings for one story. Only a few students managed to transform the stories into plays.

Story classes are very flexible classes that allow variation. The observation of students' performance indicates that short stories offer a great opportunity to practice tiered activities. Tiered activities involve grouping students based on their prior knowledge on a particular topic and providing them with the essential knowledge to ensure they reach the mastery level (Richards \& Omdal, 2007). Such activities will guarantee students' productivity and build their self-esteem by enabling them to meet the standards for their current levels. It would be more effective if flexible grouping is implemented in the previously discussed activities by giving each group of students tasks that suit their level. This will help them meet the stated objectives.

\section{Conclusion and Recommendations}

Most of the students expressed their enthusiasm for taking part in a course that relies on short stories in learning the English language. This proves that the students enjoyed these classes and that being interested in the class will ultimately increase the probability of learning. The stress-free environment and the real topics discussed created a good atmosphere for learning. As Goldberg (2006, p. 5) argued, using arts in teaching the English language "places the learner in the positions of truly working with ideas," which provides great opportunities to personalize learning. Thus, literary texts should be used in reading classes to provide students with opportunities to be exposed to this genre. It would be interesting to take this study further and compare students' perceptions of the linguistic benefits gained from literature and ELT classes. Comparing both classes would yield more valid results regarding the potential benefits of literature for English-language learners. Students' performance and involvement in both classes could also be compared.

\section{References}

Al-Mahrooqi, R. (2012). Reading literature in English: Challenges facing Omani college students. Asian EFL Journal, 57, 24-51.

Al-Mahrooqi, R., \& Denman, C. (2016). Establishing a reading culture in Arabic and English in Oman. Arab World English Journal, 7(1), 5-17.

Badger, R., \& Macdonald, M. (2010). Making it real: Authenticity, process and pedagogy. Applied Linguistics, 31(4), 578-582. https://doi.org/10.1093/applin/amq021

Butler, I. (2002). Language through literature through language: An action research report on the English 100 course at the University of North West. Literator, 23(2), 33-50. https://doi.org/10.4102/lit.v23i2.329

Fawkes, S. (2001). Using authentic materials and media in key stages 3 and 4. London, England: CILT.

Friedman, G. (2011). Learner-created lexical databases using web-based source material. ELT Journal, 63(2), 126-136. https://doi.org/10.1093/elt/ccn022

Gambrell, L. (1996). Creating classroom cultures that foster reading motivation. The Reading Teacher, 50(1), $14-25$.

Ghosn, I. (1998). Four good reasons to use literature in the primary school ELT. Seattle, WA: ERIC.

Gilmore, A. (2007). Authentic materials and authenticity in foreign language learning. Language Teaching, 40(2), 97-118. https://doi.org/10.1017/S0261444807004144

Goldberg, S. (2006). Integrating the arts: An approach to teaching and learning in multicultural and multilingual settings. Boston, MA: Pearson.

Guariento, W., \& Morley, J. (2001). Text and task authenticity in the EFL classroom. ELT Journal, 55(4), 347-353. https://doi.org/10.1093/elt/55.4.347

Heyer, S. (1997). More true stories: A beginning reader. New York, NY: Longman.

Jick, T. (1979). Mixing qualitative and quantitative methods: Triangulation in action. Administrative Science Quarterly, 24(4), 602-611. https://doi.org/10.2307/2392366

Johnson, K. (1998). Authenticity. In K. Johnson \& H. Johnson (Eds.), Encyclopedic dictionary of applied linguistics. Oxford, England: Blackwell. 
Khatib, M., Rezaei, S., \& Derakhshan, A. (2011). Literature in EFL/ESL classroom. English Language Teaching, 4(1), 201-208. https://doi.org/10.5539/elt.v4n1p201

Pathan, M. M. (2012). Advantages of using short stories in ELT classroom and the Libyan EFL learners' perceptions towards them for developing reading comprehension skill. Arab World English Journal, 4(1), $28-41$.

Peacock, M. (1997). The effect of authentic materials on the motivation of EFL learners. ELT Journal, 51(2), 144-156. https://doi.org/10.1093/elt/51.2.144

Rashid, R., Vethamani, M., \& Abdul Rahman, S. (2010). Approaches employed by teachers in teaching literature to less proficient students in Form 1 and Form 2. English Language Teaching, 3(4), 87-99. https://doi.org/10.5539/elt.v3n4p87

Richards, M., \& Omdal, S. (2007). Effects of tiered instruction on academic performance in a secondary science course. Journal of Advanced Academics, 18(3), 424-453.

Roberts, C., \& Cooke, M. (2009). Authenticity in the adult ESOL classroom and beyond. TESOL Quarterly, 43(4), 620-642. https://doi.org/10.1002/j.1545-7249.2009.tb00189.x

Siahaan, S. (2012). Using story reading technique to improve EFL young learners' vocabulary. Journal of English Teaching, 2(3), 207-222.

Stern, S. (2001). An integrated approach to literature in ESL/EFL. In M. Celce-Murcia (Ed.), Teaching English as a second or foreign language. Heinle \& Heinle.

Topping, D. N. (1968). Linguistics or literature: An approach to language. TESOL Quarterly, 2(2), 95-100. https://doi.org/10.2307/3586085

Waters, A. (2009). Ideology in applied linguistics for language teaching. Applied Linguistics, 30(1), 138-143. https://doi.org/10.1093/applin/amp005

Wong, V., Kwok, P., \& Choi, N. (1995). The use of authentic materials at tertiary level. ELT Journals, 49(4), 318-322. https://doi.org/10.1093/elt/49.4.318

Wright, A. (2008). Storytelling with children. Oxford, England: Oxford University Press. https://doi.org/10.1093/elt/49.4.318

\section{Copyrights}

Copyright for this article is retained by the author(s), with first publication rights granted to the journal.

This is an open-access article distributed under the terms and conditions of the Creative Commons Attribution license (http://creativecommons.org/licenses/by/4.0/). 